\title{
Testosterone replacement therapy for older men
}

\author{
Stephen E Borst \\ Thomas Mulligan \\ Geriatrics Research, Education, and \\ Clinical Center, North Florida/South \\ Georgia Veterans Health System, \\ Gainesville, FL, USA
}

\begin{abstract}
Despite intensive research on testosterone therapy for older men, important questions remain unanswered. The evidence clearly indicates that many older men display a partial androgen deficiency. In older men, low circulating testosterone is correlated with low muscle strength, with high adiposity, with insulin resistance and with poor cognitive performance. Testosterone replacement in older men has produced benefits, but not consistently so. The inconsistency may arise from differences in the dose and duration of testosterone treatment, as well as selection of the target population. Generally, studies reporting anabolic responses to testosterone have employed higher doses of testosterone for longer treatment periods and have targeted older men whose baseline circulating bioavailable testosterone levels were low. Most studies of testosterone replacement have reported anabolic that are modest compared to what can be achieved with resistance exercise training. However, several strategies currently under evaluation have the potential to produce greater anabolic effects and to do so in a safe manner. At this time, testosterone therapy can not be recommended for the general population of older men. Older men who are hypogonadal are at greater risk for the catabolic effects associated with a number of acute and chronic medical conditions. Future research is likely to reveal benefits of testosterone therapy for some of these special populations. Testosterone therapy produces a number of adverse effects, including worsening of sleep apnea, gynecomastia, polycythemia and elevation of PSA. Efficacy and adverse effects should be assessed frequently throughout the course of therapy.
\end{abstract}

Keywords: aging, testosterone, hypogonadism, physical function

\section{Testosterone physiology in health}

In young adult men, the hypothalamic-pituitary-gonadal axis regulates the circulating concentration of testosterone. The hypothalamic pulse generator secretes a pulse of gonadotropin releasing hormone ( $\mathrm{GnRH})$ approximately every 90 minutes (Reyes-Fuentes and Veldhuis 1993). GnRH is secreted into the hypothalamic-pituitary portal circulation where it stimulates pituitary secretion of luteinizing hormone (LH) (Veldhuis et al 1990) into the systemic circulation. LH reaches the testes and promotes both tonic and episodic Leydig cell secretion of testosterone.

Nearly all of the testosterone circulating in the blood is bound to sex hormone-binding globulin (SHBG) or albumin. The affinity of SHBG for testosterone is about 1,000-fold higher than the affinity of albumin for testosterone (Pardridge et al 1985). Thus the combined free (1\%-2\%) and albumin-bound fractions of testosterone are considered to be bioavailable (Manni et al 1985). Bioavailable testosterone in acts upon multiple target tissues and completes the feedback loop inhibiting GnRH and LH secretion.

The serum testosterone concentration displays both circadian and ultradian rhythms. The circadian rhythm results in peak testosterone serum concentrations during the early morning hours. In contrast, the ultradian rhythm has a cycle whereby the serum testosterone concentration fluctuates approximately every 90 minutes. This ultradian rhythm represents the burst-like secretory pattern of testosterone, which is superimposed on testosterone's basal or tonic secretion.

In young adult health, the feedforward (GnRH stimulates LH which stimulates testosterone secretion) and feedback (free or bioavailable testosterone inhibits 
release of GnRH and LH) components of the hypothalamicpituitary-gonadal axis maintain the serum total testosterone concentration within a "normal" range of 450-1,000 ng/dL. The mean serum total testosterone concentration for healthy young adults approximates $650 \mathrm{ng} / \mathrm{dL}$.

\section{Testosterone in older men}

Unlike female menopause, the decline in testosterone serum concentration in men is gradual, and there is much inter-individual variability. Serum testosterone concentrations decline steadily after young adulthood, and by age of 80 years, the testosterone secretion rate decreases to approximately half that of a younger man (Tenover et al 1987; Mulligan et al 1995).

The decrease in bioavailable-testosterone appears to be greater than the decline in total testosterone with advancing age, due to an age-related increase in SHBG (Rubens et al 1974). The decline in testosterone with aging has been referred to by a variety of names including male menopause, climacteric, viropause, andropause, ADAM (androgen deficiency in aging men), or age-associated hypogonadism. Longitudinal studies confirm a decline in testosterone with aging, as has been reported earlier in cross-sectional studies (Morley et al 1997; Feldman et al 2002).

With age, changes that contribute to hypogonadism occur in both the hypothalamus and testes. The rise in LH following a decrease in testosterone is considerably blunted with age (Korenman et al 1990; Veldhuis et al 2001). This is likely due to failure of the hypothalamus to generate an appropriate burst of GnRH secretion (Veldhuis et al 1994; Mulligan et al 1999). The specific mechanism may be an age-related increased sensitivity of the hypothalamic-pituitary unit to the negative feedback effect of testosterone (Winters et al 1984). In older men, the decline in circulating testosterone also correlates with changes in the testes, specifically a decline in Leydig cell number (Neaves et al 1984), development of vacuolizations and lipofuscin within the Leydig cells, and decreased Leydig cell secretion of testosterone in response to provocative stimulation with human chorionic gonadotrophin (Harman and Tsitouras 1980).

The decline in bioavailable testosterone may be at least partially responsible for the decreased muscle mass, osteoporosis, mood disturbances, and frailty seen in older men (Nunez 1982).

\section{Prevalence of age-associated hypogonadism}

The criteria for low testosterone are the same regardless of age. Symptomatic men with a total serum testosterone concentration less that $200 \mathrm{ng} / \mathrm{dL}$ are definitely hypogonadal, while those with a concentration between 200 and $300 \mathrm{ng} / \mathrm{dL}$ are probably hypogonadal. The prevalence of hypogonadism increases with advancing age; the odds ratio of hypogonadism is greater with each 10-year increase in age. Longitudinal studies in specific geographic areas of the United States and some small cross-sectional studies have demonstrated a decline in testosterone occurring as early as age 30, but usually testosterone levels remain within normal limits until men reach age 60 (Belanger et al 1994; Morley et al 1997). The prevalence of low serum total testosterone among men aged 45 years or older has been estimated to be 39\% (Mulligan et al 2006). The prevalence of symptomatic hypogonadism is considerably lower, estimated as $6 \%-12 \%$ in a group of men aged 40-60 years in the report of the Massachusetts Male Aging Study (Araujo et al 2004).

\section{Beneficial effects of testosterone on mood and cognition}

Low serum testosterone concentration in older men is associated with depression (Shores et al 2005). However, most trials of testosterone replacement have not shown improvement in depression. Two small studies in younger hypogonadal men did show short term improvement in depression with testosterone supplementation, but this effect has not been reproduced in older men (Pope et al 2003). The age of onset of depression may also be a factor in response to testosterone. Perry et al (2002) reported that 6 weeks of testosterone treatment improved depression scores in men who had onset of depression after the age of 45 years, but not in men whose depression started at a younger age.

Higher bioavailable testosterone levels are associated with better performance in cognitive tests (Barett-Connor et al 2004). Short-term trials in healthy eugonadal older men have shown improvement in verbal and spatial memory (Cherrier et al 2001; Gray et al 2005). However, longer trials have produced mixed results. Haren et al (2005) reported no improvement in cognition or memory. In a recent study by Cherrier et al (2006), older men were treated for 6 weeks with testosterone at doses of 50,100 or $300 \mathrm{mg} /$ week. Interestingly, improvements in verbal and spatial memory were observed only with the intermediate dose.

\section{Beneficial effects of testosterone on muscle and bone}

Testosterone produces substantial anabolic effects in young and middle-aged hypogonadal men (Bhasin et al 2001). In contrast, the anabolic effects of testosterone replacement 
therapy in older men have been harder to demonstrate. Among the many published trials of testosterone in older men, some report strength gains and some do not. Only a few report strength gains that can be considered substantial in comparison to the benefits of resistance exercise training. In most cases, the studies reporting significant strength gains were performed in hypogonadal subjects and employed a higher dose of testosterone, for a longer duration.

In a recent report, Nair et al (2006) describe treating a group of hypogonadal men for 24 months with a transdermal testosterone at a dose of $35 \mathrm{mg} /$ week and finding no increase in strength. However, $35 \mathrm{mg} / \mathrm{week}$ is less than a replacement dose and resulted in only a $30 \%$ increase in the circulating testosterone concentration. Studies by Brill et al (2002), Clague et al (1999), Kenny et al (2001), and Snyder et al (1999) also report small increases in strength. Brill et al treated older men for 1 month with $5 \mathrm{mg}$ testosterone/day by patch and found an improvement in stair climb time, but no increase in strength. Clague et al treated men aged 60 or more with total $\mathrm{T}$ of $400 \mathrm{ng} / \mathrm{dL}$ or less were treated with $200 \mathrm{mg}$ testosterone enanthate every two weeks by i.m. injection for 3 months and found no significant increase in strength. Kenny et al (2001) treated hypogonadal and lownormal older men with $5 \mathrm{mg}$ testosterone/day by patch for 1 year and found a $38 \%$ increase in strength with testosterone, but surprisingly also a $27 \%$ increase with placebo, with no significant difference between the two groups. Snyder et al (1999) treated older hypogonadal and eugonadal men for 36 months with $6 \mathrm{mg}$ testosterone/day by patch and found no increase in strength.

Several investigators have reported that testosterone caused moderate increases in strength; increases that are significant, but are still below than what can be obtained through resistance exercise training. Wang et al (2000) treated younger and older men (aged 19-68) with total $\mathrm{T}$ of $300 \mathrm{ng} / \mathrm{dL}$ or less with a titrated dose of testosterone gel (equivalent of 5 to $10 \mathrm{mg}$ per day) for 6 months found that the higher dose caused, a reduction in negative moods, a sizable increase in hematocrit (from 42 to 47), and modest increases in arm and leg strength. Sullivan et al (2005) conducted a 3-month study of low- or high-intensity resistance exercise training in men aged 65 or more, who were not hypogonadal (total $\mathrm{T}=480 \mathrm{ng} / \mathrm{dL}$ or less). Some subjects also received a weekly i.m. injection of $100 \mathrm{mg}$ testosterone enanthate. The addition of testosterone produced a trend toward greater increases overall, but the effect of testosterone appears to be substantial in the low-intensity training group. Considering that few men in the community will perform high-intensity training on their own, these results may indicate usefulness for testosterone therapy.

Three studies have reported substantial strength gains following testosterone treatment and all have employed doses of testosterone that are somewhat higher than replacement doses. Ferrando et al (2002) treated older hypogonadal and eugonadal men for 6 months with a biweekly injection of testosterone that was titrated to raises circulating testosterone into the normal range and resulted in an approximated doubling of circulating testosterone (from $\sim 300$ to $\sim 600 \mathrm{ng} / \mathrm{dL}$ ). Significant strength increases were observed, including a 15 $\mathrm{kg}$ increase in leg extension 1-RM strength. Page et al (2005) treated a group of older, hypogonadal men for 36 months with biweekly i.m. injections of $200 \mathrm{mg}$ testosterone enanthate and found significant improvements in hand grip strength. However, the study that best demonstrates the dose dependence is that of Bhasin et al (2005). Both older and younger men were first made hypogonadal with luprolide and then treated for 5 months with testosterone enanthate at doses ranging from $25 \mathrm{mg}$ to $600 \mathrm{mg} /$ week. Higher doses of testosterone produced large increases in strength, including an increase of $50 \mathrm{~kg}$ in leg press $1-\mathrm{RM}$ strength in older men receiving a dose of $300 \mathrm{mg} /$ week. The doses of 300 and $600 \mathrm{mg} /$ week produced a high incidence of adverse effects and a dose of $125 \mathrm{mg} /$ week was considered to be the best trade-off of beneficial and adverse effects.

The dose of testosterone also appears to be critical in determining whether increases in bone mineral density are observed. Snyder et al (1999) treated older hypogonadal and eugonadal men for 36 months with $6 \mathrm{mg}$ testosterone/day by patch and found that bone mineral density did not increase overall, but did do so in the group with the lowest pretreatment testosterone levels. However, Amory et al (2004) treated older hypogonadal men for 36 months with biweekly i.m. injections of $200 \mathrm{mg}$ testosterone enanthate and obtained substantial increases in bone mineral density, $3 \%-4 \%$ in the hip and a remarkable $10 \%$ in the lumbar spine.

\section{Beneficial effects of testosterone on the heart}

The lower rate of heart disease in women has historically been attributed to the cardioprotective effects of estrogen. Presently, this position is being reexamined. The cardioprotective effects of estrogen have come into some question and there is emerging evidence that testosterone may have cardioprotective effects of its own. Swartz and Young (1987) have shown that older men with a low circulating testosterone, a higher fraction have previously suffered a myocardial 
infarction. Testosterone supplementation in hypogonadal men improves exercise tolerance and decreases exerciseassociated ischemia in elderly patients with coronary artery disease and low (Malkin et al 2004) or low-normal (English et al 2000) testosterone. This protection may be secondary to a vasodilatory effect and/or higher pain threshold. The vasodilatory effect has been confirmed in animal models (English et al 2002). The beneficial effects are seen with both acute (Rosano et al 1999) and chronic (English et al 2000, 2002) testosterone administration, and also with low (Malkin et al 2004) and high (Rosano et al 1999) dose supplementation. However, none of these studies was long enough to show an effect on cardiovascular mortality.

Although there has been concern that testosterone therapy might adversely affect serum cholesterol and lipids, this concern has not been bourn out in controlled studies. Wang et al (2000) reported that treating hypogonadal men with testosterone gel (equivalent of 5-10 mg per day) for 6 months did not produce significant changes in LDL- or HDL-cholesterol. Whitsel et al (2001) performed a meta analysis of 19 studies involving administration of testosterone esters to older hypogonadal men and found that, on the whole, testosterone produces small, and probably offsetting, decreases in both HDL and LDL. An additional cardiac benefit of testosterone may be seen in the findings of Malkin et al (2004), who found that testosterone reduced circulating levels of tumor necrosis factor alpha and interleukin-1 beta, inflammatory cytokines that are elevated in heart failure.

\section{Risks associated with testosterone therapy}

Risks associated with testosterone replacement in elderly men include fluid retention, gynecomastia, worsening of sleep apnea, polycythemia and acceleration of benign or malignant prostatic disease (Matsumoto 2002). A high incidence of adverse effects was observed by Bhasin et al (2005) in treating older men with the very high doses of 300 and $600 \mathrm{mg} /$ week.

Among these risks, the potential effects of testosterone on the prostate are of the greatest concern. These concerns stem from the known action of testosterone in accelerating active prostate cancer and from the high prevalence of early-stage prostate cancer in elderly men. While approximately $10 \%$ of men will develop clinically manifest prostate cancer in their lifetime and $\sim 3 \%$ will die of the disease, autopsy data show that $42 \%$ of men over the age of 60 have early-stage prostate cancer (Mikuz 1997). Clinical trials to date are not large enough or long enough to determine the potential effects of testosterone treatment on prostate cancer. Although Zitzmann et al (2003) have shown that replacement and slightly higher doses of testosterone produce a predictable and moderate degree of prostate enlargement, existing data do not indicate that testosterone promotes prostate cancer. Hajjar et al (1997) treated elderly men with a replacement dose of testosterone and found no increase in prostate cancer during a 2-year follow-up. Agarwal and Oefelein (2005) administered testosterone for 19 months to hypogonadal patients with a history of prostate cancer and prostatectomy, but whose recent PSA levels were low. Treatment significantly elevated circulating testosterone and improved quality of life without elevating PSA.

Patients should be evaluated one month after initiation of treatment and the dose should be increased if symptoms of hypogonadism have not improved. Rhoden and Morgentaler (2004) have reviewed the adverse effects and recommend the following monitoring. Safety monitoring should include sleep apnea, voiding symptoms, serum testosterone, PSA and hemoglobin or hematocrit and should be performed several times during the first year and yearly thereafter.

\section{Who might benefit from testosterone replacement therapy?}

In response to concerns over the efficacy and risks of hormonal replacement in the elderly, the NIH commissioned an assessment by the Institute of Medicine (IOM). The IOM report states that there is insufficient evidence to conclude that testosterone treatment in older men has well established benefits. In addition, the IOM recommended that small and medium-sized trials be conducted to assess the efficacy of testosterone for treating muscle weakness, osteoporosis, sexual dysfunction, cognitive impairment and depression (Liverman and Blazer 2004). The IOM does not recommend prevention trials or trials for all hypogonadal older men. While we agree with these recommendations, at least two other avenues of exploration deserve attention.

First, while replacement doses of testosterone do not consistently produce substantial increases in strength, Page et al (2005) and Bhasin et al (2005) have shown that higher doses of testosterone do produce such increases. Higher doses of testosterone also produce more adverse effects, especially prostate effects. Strength, especially lower body strength, remains an important facto limiting the independence of older people. Currently, alternative strategies are being developed, aimed at stimulating the androgen receptor more powerfully, without producing added adverse effects. One such strategy is to administer a higher dose of testosterone with 
the addition of a 5-alpha reductase inhibitor to prevent the prostate symptoms. Another strategy is the use of selective androgen receptor modulators (SARMs), currently under development at several pharmaceutical firms.

A second avenue where more research is needed is testosterone therapy for special populations of men who are at risk for development of catabolic states and muscle wasting. Testosterone might be used to prevent disuse muscle atrophy following knee or hip replacement. A study by Amory et al (2002) suggests that treating men with testosterone before knee replacement surgery improved functional independence after. While these results were not dramatic, one limitation of the study is that testosterone therapy did not continue after surgery, ie, during the period of muscle atrophy. In addition, hypogonadism and muscle wasting are associated with a number of conditions that are more common in older men including COPD (Debigare et al 2003), coronary artery disease (Rosano et al 2006), glucocorticoid therapy (Salehian and Kejriwal 1999), and acute ischemic stoke (Jeppesen et al 1996). It is likely that in some cases, testosterone therapy may prevent catabolic/muscle wasting syndromes associated with these conditions.

In conclusion, while it is true that most studies of testosterone replacement in older men have not produced substantial increases in strength, testosterone therapy continues to hold promise for older men. Testosterone may be of greater use in special populations who are at risk for development of a catabolic state (eg, patients recovering from a long period of bed rest or joint replacement). In addition, there is promise that strategies will be developed to stimulate the testosterone pathway more robustly and to do so in a safe manner. If so, there may be indication for use of such therapy in a broader segment of the population of older men. In the meantime, truly hypogonadal men (those who are symptomatic men and have a serum testosterone concentration below $200 \mathrm{ng} / \mathrm{dL}$ ) who have no contraindications to testosterone replacement therapy (eg, prostate cancer) may benefit from testosterone replacement regardless of whether they are 30 or 80 years of age.

\section{References}

Agarwal PK, Oefelein MG. 2005. Testosterone replacement therapy after primary treatment for prostate cancer. $J$ Urol, 173:533-6.

Amory JK, Chansky HA, Chansky KL, et al. 2002. Preoperative supraphysiological testosterone in older men undergoing knee replacement surgery. $J$ Am Geratr Soc, 50:1698-701.

Amory JK, Watts NB, Easley KA, et al. 2004. Exogenous testosterone or testosterone with finasteride increases bone mineral density in older men with low serum testosterone. $J$ Clin Endocrinol Metab, 89:503-10.

Araujo AB, O'Donnell AB, Brambilla DJ, et al. 2004. Prevalence and incidence of androgen deficiency in middle-aged and older men: estimates from the Massachusetts Male Aging Study. J Clin Endocrinol Metab, 89:5240-7.
Barett-Connor E, Goodman-Gruen D, Patay B. 1999. Endogenous sex hormones and cognitive function in older men. $J$ Clin Endocrinol Metab, 84:3681-5.

Belanger A, Candas B, Dupont A, et al. 1994. Changes in serum concentrations of conjugated and unconjugated steroids in 40- and 80-year old men. J Clin Endocrinol Metab, 79:1086-90.

Bhasin S, Woodhouse L, Casaburi R, et al. 2005. Older men are as responsive as young men to the anabolic effects of graded doses of testosterone on the skeletal muscle. J Clin Endocrinol Metab, 90:678-88.

Bhasin S, Woodhouse L, Storer TW. 2001. Proof of the effect of testosterone on skeletal muscle. J Endocrinol, 170:27-38.

Brill K, Weltman AL, Gentili A, et al. 2002. Single and combined effects of growth hormone and testosterone administration on measures of body composition, physical performance, mood, sexual function, bone turnover, and muscle gene expression in healthy older men. $J$ Clin Endocrinol Metab, 87:5649-57.

Cherrier MM, Asthana S, Plymate S, et al. 2001. Testosterone supplementation improves spatial and verbal memory in healthy older men. Neurology, 57:80-8.

Cherrier MM, Matsumoto AM, Amory JK, et al. 2006. Characterization of verbal and spatial memory changes from moderate to supraphysiological increases in serum testosterone in healthy older men. Psychoneuroendocrinology [Epub ahead of print].

Clague JE, Wu FC, Horan MA. 1999. Difficulties in measuring the effect of testosterone replacement therapy on muscle function in older men. Int $J$ Androl, 22:261-5.

Debigare R, Marquis K, Cote CH, et al. 2003. Catabolic/anabolic balance and muscle wasting in patients with COPD. Chest, 124:83-9.

English KM, Jones RD, Jones TH, et al. 2002. Testosterone acts as a coronary vasodilator by a calcium antagonistic action. $J$ Endocrinol Invest, 25:455-8.

English KM, Steeds RP, Jones TH, et al. 2000. Low-dose transdermal testosterone therapy improves angina threshold in men with chronic stable angina: A randomized, double-blind, placebo-controlled study. Circulation, 102:1906-11.

Feldman HA, Longcope C, Derby CA, et al. 2002. Age trends in the level of serum testosterone and other hormones in middle-aged men: longitudinal results from the Massachusetts male aging study. J Clin Endocrinol Metab, 87:589-98.

Ferrando AA, Sheffield-Moore M, Yeckel CW, et al. 2002. Testosterone administration to older men improves muscle function: molecular and physiological mechanisms. Am J Physiol, 282:E601-7.

Gray PB, Singh AB, Woodhouse LJ, et al. 2005. Dose-dependent effects of testosterone on sexual function, mood, and visuospatial cognition in older men. J Clin Endocrinol Metab, 90:3838-46.

Hajjar RR, Kaiser FE, Morley JE. 1997. Outcomes of long-term testosterone replacement in older hypogonadal males: a retrospective analysis. J Clin Endocrinol Metab, 82:3793-6.

Haren MT, Wittert GA, Chapman IM, et al. 2005. Effects of oral testosterone undecanoate on visuospatial cognition, mood and quality of like in elderly men with low-normal gonadal status. Maturitas, 50:124-33.

Harman SM, Tsitouras PD. 1980. Reproductive hormones in aging men. I. Measurement of sex steroids, basal luteinizing hormone, and Leydig cell response to human chorionic gonadotropin. J Clinic Endocrinol Metab, 51:35-40.

Jeppesen LL, Jorgensen HS, Nakayama H, et al. 1996. Decreased serum testosterone in men with acute ischemic stroke. Arterioscler Thromb Vasc Biol, 16:749-54.

Kenny AM, Bellantonio S, Gruman CA, et al. 2001. Effects of transdermal testosterone on bone and muscle in older men with low bioavailable testosterone levels. J Gerontol Med Sc, 56A:M266-72.

Korenman SG, Morley JE, Mooradian AD, et al. 1980. Secondary hypogonadism in older men: its relation to impotence. $J$ Clin Endocrinol Metab, 71:963-9.

Liverman CT, Blazer DG. 2004. Testosterone and Aging: Clinical Research Directions. Washington, DC: The National Academic Press. 
Malkin CJ, Pugh PJ, Jones RD, et al. 2004. The effect of testosterone replacement on endogenous inflammatory cytokines and lipid profiles in hypogonadal men. J Clin Endocrinol Metab, 89:3313-18.

Malkin CJ, Pugh PJ, Morris PD, et al. 2004. Testosterone replacement in hypogonadal men with angina improves ischaemic threshold and quality of life. Heart, 90:871-6.

Manni A, Pardridge WM, Cefalu W, et al. 1985. Bioavailability of albumin bound testosterone. J Clinical Endocrinol Metab, 61:705-10.

Matsumoto AM. 2002. Andropause: clinical implications of the decline in serum testosterone levels with aging in men. J Gerontol A Biol Sci Med Sci, 57:M76-99.

Mikuz G. 1997. Pathology of prostate cancer. Adv Clin Pathol, 1:21-4.

Morley JE, Kaiser FE, Perry HM, et al. 1997. Longitudinal changes in testosterone, luteinizing hormone, and follicle-stimulating hormone in healthy older men. Metabolism, 46:410-13.

Mulligan T, Frick MF, Zuraw QC, et al. 2006. Prevalence of hypogonadism in males aged at least 45 years: the HIM study. Int J Clin Pract, 60:762-9.

Mulligan T, Iranmanesh A, Gheorghiu S, et al. 1995. Amplified nocturnal LH secretory burst frequency with selective attenuation of pulsatile (but not basal) testosterone secretion in healthy aged men: Possible Leydig cell desensitization to endogenous LH signaling. $J$ Clin Endocrinol Metab, 80:3025-31.

Nair KS, Rizza RA, O'Brien P, et al. 2006. DHEA in elderly women and DHEA or testosterone in elderly men. $N$ Engl J Med, 355:1647-59.

Neaves WB, Johnson L, Porter JC, et al. 1984. Leydig cell number, daily sperm production, and serum gonadotropin levels in aging men. J Clinical Endocrinol Metab, 59:756-63.

Nunez AA. 1982. Dose dependent effects of testosterone on feeding and body weight in male rats. Behav Neurol Biol, 34:445-9.

Page ST, Amory JK, Bowman FD, et al. 2005. Exogenous testosterone (T) alone or with finasteride increases physical performance, grip strength, and lean body mass in older men with low serum T. J Clin Endocrinol Metab, 90:1502-10.

Pardridge WM, Landaw EM. 1985. Testosterone transport in brain: Primary role of plasma protein-bound hormone. Am J Physiol, 249:E534-42.

Perry PJ, Yates WR, Williams RD, et al. 2002. Testosterone therapy in latelife major depression in males. J Clin Psychiatry, 63:1096-101.

Pope HG Jr, Cohane GH, Kanayama G, et al. 2003. Testosterone gel supplementation for men with refractory depression: a randomized, placebo-controlled trial. Am J Psychiatry, 160(1):105-11.

Reyes-Fuentes A, Veldhuis JD. 1993. Neuroendocrine physiology of the normal male gonadal axis. Endocrinol Metabol Clin North America, 22:93-124.

Rhoden EL, Morgentaler A. 2004. Risks of testosterone-replacement therapy and recommendations for monitoring. $N$ Engl J Med, 350:482-92.

Rosano GM, Leonardo F, Pagnotta P, et al. 1999. Acute anti-ischemic effect of testosterone in men with coronary artery disease. Circulation, 99:1666-70.

Rosano GM, Sheiban I, Massaro R, et al. 2006. Low testosterone levels are associated with coronary artery disease in male patients with angina. Int $J$ Impot Res, Aug 31x [Epub ahead of print].
Rubens R, Dhont M, Vermeulen A. 1974. Further studies on Leydig cell function in old age. J Clin Endocrinol Metab, 39:40-5.

Salehian B, Kejriwal K. 1999. Glucocorticoid-induced muscle atrophy: mechanisms and therapeutic strategies. Endocr Pract, 5:277-81.

Shores MM, Moceri VM, Sloan KL, et al. 2005. Low testosterone levels predict incident depressive illness in older men: effects of age and medical morbidity. J Clin Psychiatry, 66:7-14.

Snyder PJ, Peachey H, Hannoush P, et al. 1999. Effect of testosterone treatment on bone mineral density in men over 65 years of age. J Clin Endocrinol Metab, 84:1966-72.

Snyder PJ, Peachey H, Hannoush P, et al. 1999. Effect of testosterone treatment on body composition and muscle strength in men over 65 years of age. J Clin Endrocrinol Metab, 84:2646-53.

Sullivan DH, Roberson PK, Johnson LE, et al. 2005. Effects of muscle strength training and testosterone in frail elderly males. Med Sci Sports Exerc, 37:1664-72.

Swartz CM, Young MA. 1987. Low serum testosterone and myocardial infarction in geriatric male inpatients. $J$ Am Geriatr Soc, 35:39-44.

Tenover JS, Matsumoto AM, Plymate SR, et al. 1987. The effects of aging in normal men on bioavailable testosterone and luteinizing hormone secretion: response to clomiphene citrate. J Clin Endocrinol Metab, 65:1118-26.

Veldhuis JD, Iranmanesh A, Johnson ML, et al. 1990. Twenty-four-hour rhythms in plasma concentrations of adenohypophyseal hormones are generated by distinct amplitude and/or frequency modulation of underlying pituitary secretory bursts. J Clin Endocrinol Metab, 71:1616-23.

Veldhuis JD, Swart A, Mulligan T, et al. 2001. Muting of androgen negative feedback unveils impoverished gonadotropin-releasing hormone/ luteinizing hormone secretory reactivity in healthy older men. J Clin Endocrinol Metab, 86:529-35.

Veldhuis JD, Urban RJ, Dufau ML. 1994. Differential responses of biologically active luteinizing hormone secretion in older versus young men to interruption of androgen negative feedback. J Clin Endocrinol Metab, 79:1763-70.

Wang C, Swerdloff RS, Iranmanesh A, et al. 2000. Testosterone Gel Study Group. Transdermal testosterone gel improves sexual function, mood, muscle strength and body composition parameters in hypogonadal men. $J$ Clin Endocrinol Metab, 85:2839-53.

Whitsel EA, Boyko EJ, Matsumoto AM, et al. 2001. Intramuscular testosterone esters and plasma lipid levels in hypogonadal men: a meta-analysis. Am J Med, 111:261-9.

Winters SJ, Sherins RJ, Troen P. 1984. The gonadotropin-suppressive activity of androgen is increased in elderly men. Metabolism, 33:1052-9.

Zitzmann M, Depenbusch M, Gromoll J, et al. 2003. Prostate volume and growth in testosterone-substituted hypogonadal men are dependent on the CAG repeat polymorphism of the androgen receptor gene. J Clin Endocrinol Metab, 88:2049-54. 